\title{
Note
}

\section{Functional and Pasting Properties of Locally Grown and Imported Exotic Rice Varieties of Malaysia}

\author{
Rachel Thomas ${ }^{1}$, Rajeev Bhat ${ }^{1 *}$, Yeoh Tow $\mathrm{KuANG}^{2}$ and Wan-Nadiah Wan Abdullah ${ }^{3}$ \\ ${ }^{1}$ Food Technology Division, School of Industrial Technology, Universiti Sains Malaysia, Penang 11800, Malaysia \\ ${ }^{2}$ Tourism and Culinary Arts, Taylor's University, Lakeside Campus, No. 1, Jalan Taylor's, 47500 Subang Jaya, Selangor Darul \\ Ehsan, Malaysia \\ ${ }^{3}$ Bioprocess Technology Division, School of Industrial Technology, Universiti Sains Malaysia, Penang 11800, Malaysia.
}

Received March 8, 2013 ; Accepted November 22, 2013

In the present study, functional and pasting properties of 3 locally grown exotic rice varieties were compared with 3 popular imported rice varieties. Various parameters such as water and oil absorption capacities, gelation properties, pH, water activity, emulsion activity and stability, foaming capacity and pasting properties were evaluated. Results obtained showed significant differences in water absorption (3.82 - 10.86) and oil absorption capacities $(2.18-6.37)$ with $\mathrm{pH}$ and aw varying between $6.07-6.45$ and $0.62-0.68$, respectively among various rice samples. Emulsifying activity $(5.48 \%)$ and stability $(\mathbf{9 8 . 3 \% )}$ ), and foaming capacities $(3.98 \%)$ were highest in glutinous rice. Significant differences were observed in pasting parameters of rice starch especially in relevance to peak time, peak viscosity, final viscosity (range $513-1077 \mathrm{cP}$ ) and setback. Results generated in this study pertinent to functional and pasting properties is envisaged to be useful in exploiting the potentiality of local rice grain varieties at international market levels to develop new rice based food products.

Keywords: functional properties, total starch content, pasting properties, exotic rice

\section{Introduction}

Rice (Oryza sativa L.) is one of the most extensively grown and consumed cereal crops, especially among the Asians (app. 95\% of the residing production) (Bhattacharjee et al., 2002; Ramesh et al., 2009; Hasjima et al., 2013). Depending on the growing regions, various popular dishes are prepared by utilizing rice in combination with other ingredients used in smaller percentages (Zhou et al., 2002).

Determining the functional properties such as water and oil absorption capacities, emulsifying activity and stability, and foaming capacity of rice are highly significant as this can help in deciding whether the grains have promising usage in the food ingredient industry or not (Theerakulkait et al., 2006; Marerat et al., 2011). In addition, determining the pasting properties is essential as it can aid in deciding the cooking stability, water- binding capacity and baking quality of starch.

As functional and pasting properties tends to play a pivotal role in determining the quality of rice or rice based food product, it is highly essential to provide details pertaining to these parameters, especially for the locally grown rice varieties. Apart from the physical, textural and gelatinization properties, starch components can also be an influential parameter in determining the quality of a rice product (Juliano, 1985; González et al., 2004). Starch (encompassing nearly $90 \%$ on d.w.) is one of the principal components of rice grains that can have a significant influence on the texture of cooked grains (Iturriagaa et al., 2010; Mutters and Thompson, 2009).

Above all, consumers' acceptance is very important in choosing the right variety of rice when quality criteria are set, it is highly important to identify and provide details on the positive aspects of 
local rice grain varieties. Hence, based on these facts, the present study was undertaken to evaluate the functional and pasting properties of different locally grown rice varieties and were compared with those of popular, imported rice varieties in order to provide baseline information's which are envisaged to be useful while developing new rice based food products or food formulations.

\section{Materials and Methods}

Materials In total, six popular rice varieties (local and imported) were purchased from the local supermarket (Penang, Malaysia). The local rice varieties were the White rice (medium grain type, grown in Kedah region of Malaysia), Bario rice (grown in the Bario region of Sabah, East Malaysia) and Brown rice variety (grown in Kedah region of Malaysia). Whereas, imported rice varieties used for comparison included: Black rice and glutinous rice (from Thailand) and Basmati rice (from Pakistan). Only whole rice grains which maintained $75 \%$ of its grain length and without any physical damage was selected for analysis. Rice samples were individually ground to a fine powder (30 mesh size) using a Waring blender (Panasonic MX-898 M, Malaysia, packed in air tight plastic bags and were stored at $4{ }^{\circ} \mathrm{C}$ for future usage).

\section{Physical Properties}

$\mathrm{pH}$ and water activity measurements The $\mathrm{pH}$ and water activity (aw) in rice samples were measured based on the method of Cuevas-Rodriguez et al. (2006). In brief, rice flour samples (10 g) were suspended individually in $200 \mathrm{~mL}$ of boiling distilled water and the resulting slurry obtained (after cooling) was centrifuged at room temperature $\left(25 \pm 1^{\circ} \mathrm{C}\right.$ ) in an orbital shaker (at $1500 \mathrm{rpm}$ for 20 min.) (Janke and Kunkel model KS501 D. IKA-Labortechnik, Germany). The $\mathrm{pH}$ reading for flour samples were recorded using a pH meter (Mettler-Toledo, Switzerland).

For measuring water activity, five grams of each rice sample was tempered at $25^{\circ} \mathrm{C}$ using a Hydrometer Aqua Lab Model CX-2 (Decagon Devices Inc., Pullman, WA, USA), and after the headspace equilibrium was attained, and readings were taken. Measurements for both $\mathrm{pH}$ and aw were done in triplicates.

\section{Functional Properties}

Water and oil absorption capacity The water and oil absorption capacities (WAC and OAC) in rice samples were ascertained based on the method described by Beuchat (1977), with some minor modifications. Briefly, to $25 \mathrm{~mL}$ of distilled water or refined Sunflower oil (for OAC), a known weight of powdered rice samples (2.5 g) were added in centrifuge tubes (50 mL capacity). The contents in tubes were centrifuged (Centrifuge Model: Kubota 4000 Tokyo, Japan) for 15 minutes at $3500 \mathrm{~g}$, and the mixture acquired was left standing at room temperature $\left(25 \pm 1{ }^{\circ} \mathrm{C}\right)$ for $30 \mathrm{~min}$. The residue obtained after centrifugation was weighed, followed by calculation of water and oil absorption capacities (WAC and OAC) using the following equation:

$$
\text { WAC and OAC }=\frac{\text { Millilitres of water or oil absorbed }(\mathrm{mL})}{\text { Weight of dry sample }(\mathrm{g})}
$$

Foaming capacity The foaming capacity (FC) in rice samples were determined based on method reported by Narayana and Narasinga Rao (1982), with some modifications. Briefly, $100 \mathrm{~mL}$ of distilled water was mixed with $2.5 \%(\mathrm{w} / \mathrm{v})$ of rice flour and was whipped thoroughly at low speed in a Waring blender (for $5 \mathrm{~min}$.) and the foam volume formed after 30 s was recorded. The percentage increase in foam volume after 30s was considered as foaming capacity. Finally, the foaming capacity (FC) in the rice samples was calculated by using the following formula:

$$
\text { FC }(\%)=\frac{\text { Volume of increase in foam layer }(\mathrm{mL})}{\text { Original foam volume }(\mathrm{mL})} \times 100 \%
$$

Least gelation capacity (LGC) Gelation properties of rice flour were performed based on method described by Coffman and Garcia (1977). In brief, suspensions were prepared by blending rice flour in distilled water (concentrations 2 to 20\%). Further, each suspension $(10 \mathrm{~mL})$ were placed in clean test tubes, and heated in boiling water bath (for $1 \mathrm{~h}$ ). Followed by this, samples were cooled (for $2 \mathrm{~h}$ ) in an refrigerator at $4{ }^{\circ} \mathrm{C}$. The lowest concentration wherein samples did not slide (or fall down) easily (on inverting the test tube) was considered as least gelation concentration.

Emulsifying properties The emulsifying activity and emulsion stability (EA and ES) was achieved based on the method described by Sathe et al. (1982). Briefly, 7\% (w/v) of rice flour suspension was dispersed in $100 \mathrm{~mL}$ of distilled water and the mixture was homogenized for 30s at $11000 \mathrm{rpm}$ using a homogenizer (Polyton homogenizer, Kinematica, PT-1200 E, Switzerland). Further, $100 \mathrm{~mL}$ of sunflower refined oil was added to this and the mixture was again homogenized for $1 \mathrm{~min}$. The emulsions obtained were centrifuged at $1200 \mathrm{~g}$ for $5 \mathrm{~min}$ in $50 \mathrm{~mL}$ graduated centrifuge tubes (Model: Kubota 4000 Tokyo, Japan). The volume of the remaining emulsion was measured and emulsifying activity (EA) was calculated using the following equation:

$$
\text { EA }(\%)=\frac{\text { Vol. of emulsified layer }(\mathrm{mL})}{\text { Vol. of whole layer in centrifuge tube }(\mathrm{mL})} \times 100
$$

Emulsion stability was determined by heating the emulsions prepared by the same procedure described above at $80^{\circ} \mathrm{C}$ for $30 \mathrm{~min}$. The emulsions obtained were cooled at room temperature and centrifuged at $1200 \mathrm{x}$ g for $5 \mathrm{~min}$. Emulsion stability was calculated using the following equation:

$$
\text { ES }(\%)=\frac{\text { Volume of remaining emulsified layer }}{\text { Original emulsion volume }(\mathrm{mL})} \times 100
$$


Determination of total starch content Total starch (TS) was determined enzymatically according to the method described by Goni et al. (1996). Rice samples (30 mg) were dispersed in $6 \mathrm{~mL}$ of $2 \mathrm{M}$ potassium hydroxide $(\mathrm{KOH})$ and were incubated for $30 \mathrm{~min}$ at room temperature to disperse all starch fractions. About $60 \mu \mathrm{l}$ of amyloglucosidase (]REF 102 857, Boehringer) was added to hydrolysed the starch. The samples were then incubated at $60^{\circ} \mathrm{C}$ for $45 \mathrm{~min}$ in a controlled shaking water bath. After centrifugation (10 min, $3000 \mathrm{~g}$ ), the supernatant obtained was collected, transferred into a volumetric flask $(50 \mathrm{~mL})$ and final volume was made up with distilled water. Different concentrations of standard solutions, anhydrous D-glucose $(10-60 \mathrm{ppm})$ were prepared. Glucose oxidase/peroxidase assay (SERA-PAK Plus ${ }^{\circledR}$, Bayer de México, S.A. de C.V., Edo, De México) was used to determine the glucose content. $1 \mathrm{~mL}$ glucose oxidase peroxidase (GOD-PAP) reagent was added into a part of diluted sample mixed with standard solution $(0.1 \mathrm{~mL})$ in their respective test tubes. Further, this was incubated in a water bath for $30 \mathrm{~min}$ (at $37^{\circ} \mathrm{C}$ ), and the absorption was measured at $510 \mathrm{~nm}$ using UV-spectrophotometer (Shimadzu Co. Japan Model AA-6650). The GOD-PAP reagent was used as blank for zero adjustment of the spectrophotometer. Glucose concentration was converted to starch using a 0.9 factor.

Pasting Properties The Pasting properties of rice starch was determined using Rapid Visco Analyzer (RVA Model 4, Newport Scientific Inc., Warriewood, Australia). Briefly, $3.5 \mathrm{~g}$ of rice flour sample was weighed in an aluminium canister and deionized water was added. For the experiment, temperature-time conditions included a heating phase from 50 to $95^{\circ} \mathrm{C}$ at $4{ }^{\circ} \mathrm{C} / \mathrm{min}$, a holding phase at $95^{\circ} \mathrm{C}$ for $3 \mathrm{~min}$, a cooling phase from $95^{\circ}$ to $50^{\circ} \mathrm{C}$ at the rate of $4^{\circ} \mathrm{C} / \mathrm{min}$ and a holding phase at $50^{\circ} \mathrm{C}$ for 2 minutes. For the pasting curve, the measured parameters included: peak temperature, peak viscosity, breakdown, final viscosity, setback and peak time was obtained. Results were expressed in centipoise and minutes (for peak time).

Statistical analysis Statistical analysis of the generated data were subjected to one-way analysis of variance (ANOVA) and Tukey's HSD post-hoc test using SPSS software (SPSS version 17.0 SPSS Inc., Wacker Drive, Chicago, IL, USA), with the level of significance determined at $p<0.05$.

\section{Results and Discussion}

Significance of rice varieties used in the present study In the present study, we used 6 popular rice varieties marketed in Malaysia. The white rice (medium grain type) is one of the milled rice types wherein the outer layers (husk, bran and germs) are removed. This rice is popular owing to its smooth flavour, and is believed to balance well with locally prepared sauces or curries. Additionally, the local white rice variety is considered to have long storage life, and this can be extended even further if the grains are stored air-tight. The brown rice (un-milled rice) variety used in this study, encompassed the whole kernel with its bran layer still unremoved. The distinct characteristic feature differentiating brown from white rice is not only the colour, but also the milling process. Generally, in brown rice, the hull are removed but bran and the germ are retained. Brown rice is considered to have high fibre content, and is nutritious with mild 'nutty' flavour. Traditionally, this rice is considered more 'chewier' than white rice with a shorter shelf life owing to the presence of oil in the germ (causing rancidity). The 'Bario' rice used in the present study is considered to be an exotic variety with a unique taste and cooking quality. Cooked grain has a soft texture with a mild and delicate aroma and is longer compared to raw rice grain. Bario rice is grown at high altitudes (above $1000 \mathrm{~m}$ sea level) and has high market value as it is considered to be an organic produce, with no usage of chemical fertilizers or pesticides during its cultivation.

On the other hand, the imported rice varieties as that of glutinous rice (popular as sweet rice, origin of Thailand and Laos) is particularly preferred owing to its sticky and dense texture obtained on cooking. In addition, this rice is reported not to contain any gluten (Wanchanaa et al., 2003). Glutinous rice are mainly used in stabilizing sauces or gravies (Juliano and Hicks, 1996). Apart from making sweet delicacies or desserts, this rice is also used by some of the Asian communities to prepare sushi and rice crackers. Black rice (popular as forbidden rice) is an unmilled rice (black husks are not removed, thus has increased nutritional value) and is considered as heirloom variety of rice cultivated in Asia. Black rice is rich in fibre and iron content, and is highly popular for preparing noodles, exotic desserts and sushi. Even though referred to as 'black rice', the colour of black rice is infact 'deep purple to burgundy' owing to its high anthocyanin content. Black rice is slightly sweet, has an unique taste with nut like flavour. Parallel to brown rice, even the black rice undergoes spoilage easily and has short storage life. It has been reported that consumption of black rice can lead to the prevention of cancer, heart problems, atherosclerosis, and infectious diseases (Barron, 2010). The last variety of rice used in this study was the 'Basmati' rice, which is characterized by its long and slender grain. This rice is cultivated mainly in India and Pakistan and encompasses an exquisite aroma that can be is associated with the aging process (reduction in moisture content) (Wass, 2011). Compared to most of the rice varieties, Basmati rice has good cooking properties and has soft texture, distinct scent, and good cooked elongation ratio (Bligh, 2000; Arora et al., 2007). Basmati rice is recommended for people suffering from diabetes as it is known to have a lower glycaemic index (British Dietetic Association, 2011).

Physical Properties: $p H$ and $a_{w}$ In Figure 1 (A, B), the values obtained for $\mathrm{pH}$ and water activity are depicted. The $\mathrm{pH}$ values of rice flour varied significantly between 6.07 to 6.45 . Based on the results obtained, it could be stated that the rice samples to low acidic food. The organic acids present in rice were minor constituents as compared to starch and protein content. It has been reported that the organic acids (such as fatty acids, amino acids and 

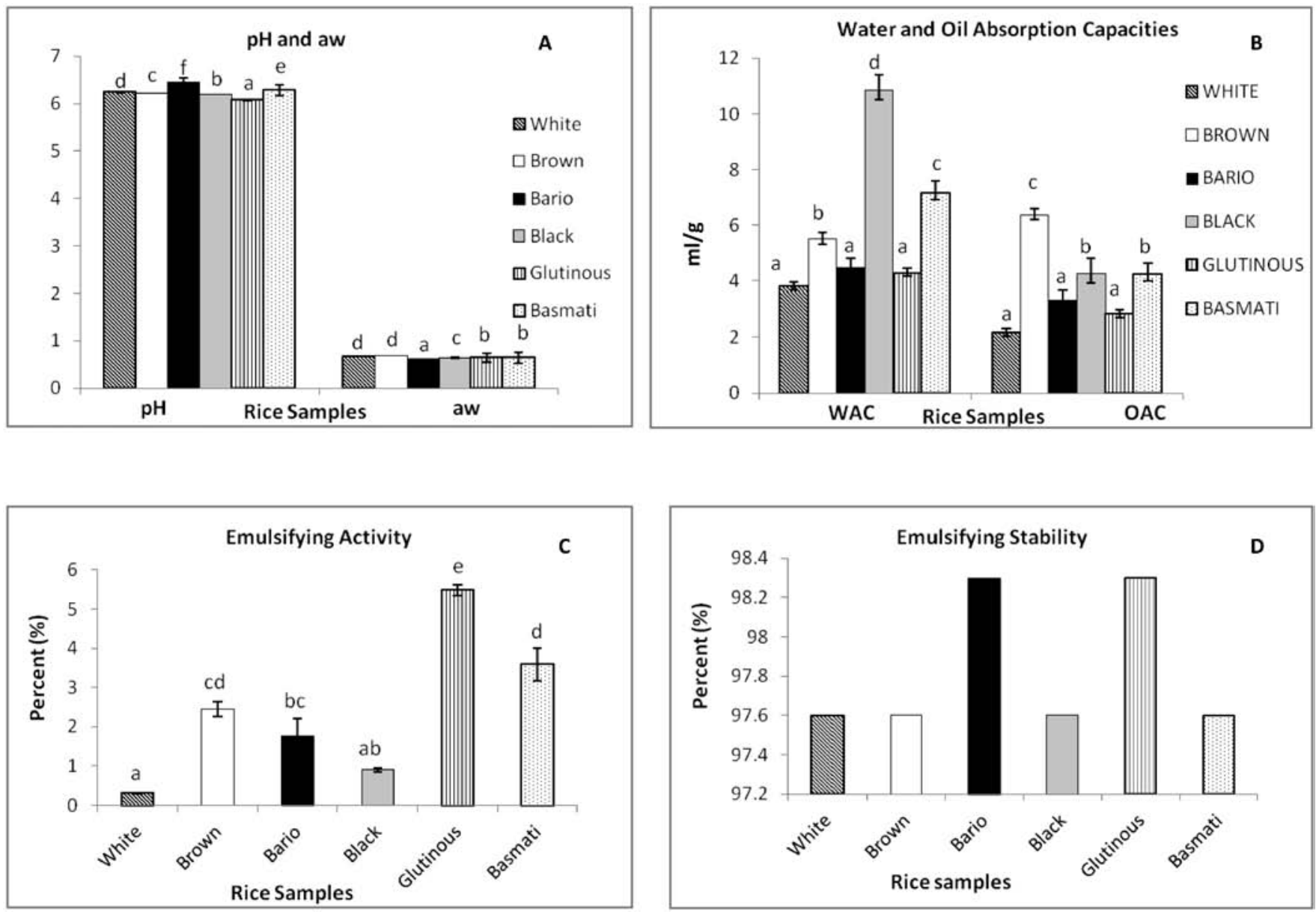

Fig. 1. A, pH and aw of rice varieties; B, Water and Oil Absorption capacity of rice varieties, C, Emulsifying activity of rice varieties; D, Emulsifying stability of rice varieties. Values are mean \pm standard deviation, same letter superscripted in the same column are not significantly different from each other at $p<0.05$.

phytic acids) to have been formed during storage of rice owing to deterioration of lipids, carbohydrates and proteinaceous compounds (MoniQa, 2012). Also, these metabolically active compounds have been regarded to be good indicators of quality (Houston et al., 1963). In addition, $\mathrm{pH}$ or the acidic nature of rice grain can influence colour changes, and can be correlated to poor eating qualities when acidity increases in rice grains.

Water activity (aw) is an important criterion which is based on Raoult's law of colligative properties (p/p0) and is explained as the relative vapour pressure of the solute above a sample divided by the vapour pressure of pure water (determined at the same temperature). Water activity can influence the microbial quality and overall safety as rice grains are generally exposed to varied range of temperatures from pre-harvest upto post-harvest stages (Noorlidah et al., 2000). As microbial growth can be controlled and reduced by monitoring the water activity levels it is very important to provide details on this parameter in relevance to rice grain. In the present study, water activity range for all rice samples was between $0.62-0.68$. Growth of majority of the spoilage microorganisms can be inhibited if the water activity is below 0.9 , and at 0.6 all microbial growths can be completely eliminated (FAO, 1998). This is because water is made unavailable due to its tight-knitted bonds.

\section{Functional properties}

Water and oil absorption capacity (WAC and OAC) Water plays a significant role in bringing about a range of significant changes during gelatinization of starch as well as it influences other functional properties. Determining WAC is important as it assists in the formulation of various food products such as bread and soups (Oshodi and Adeladun, 1993; Bhat et al., 2008). Results obtained for the WAC and OAC for the different rice varieties evaluated in the present study are shown in Figure $1 \mathrm{~B}$. Accordingly, WAC ranged between $3.82-10.86 \mathrm{~mL} / \mathrm{g}$. White rice had the lowest water absorption capacity while black rice had the highest. The differences observed in WAC can be attributed to the starch composition namely the amylose/amylopectin ratio (Sage $\mathrm{V}$ foods, 2000). It is reported that low WAC corresponds to high amylose contents of rice (Williams et al., 2002; Ihegwuagu et al., 2009).

OAC measures the capability of proteins to physically bind fat by capillary gravitation. In the present study, the range recorded for OAC was between $2.18-6.37 \mathrm{~mL} / \mathrm{g}$. OAC for brown rice was significantly high compared to all other local and imported varieties. OAC can influence not only the oil retention in a food 
product, but can also determine the level of flavour retention and 'mouth-feel' (Fasoyiro et al., 2010). The differences in OAC has been attributed to the variations in the amylose/amylopectin ratio as well as their chain length distribution (Perez et al., 2002; Lawal et al., 2004).

Foaming capacity Foaming activity is considered to be an assessment on the capability of a liquid to form foam after aeration (Khuwijitjaru et al., 2007). The surface active effects of protein can help in the formation of foam by lowering the surface tension at the 'water-air' interfaces (Guan et al., 2007). In addition, foam capacity can be formed exclusively if the aqueous phase allows protein to solubilise as well as unfold to surround the gas or the air droplets with a strong layer of protein (Tang et al., 2002). In the present study, foaming capacity of rice samples ranged between 0.97 to $3.96 \%$. The lowest foaming capacity was recorded in white and basmati rice, whereas glutinous rice exhibited highest foaming capacity. Recently, Islam et al. (2012) have reported on foaming capacity of brown rice flour, which was four times higher than our observation. This difference can be attributed to the variation in molecular flexibility as indicated by Sengupta and Damodaran (1998). Rice with acceptable foaming capacity possesses high potential to be incorporated in various baked products (e.g. rice cakes and bread) (Akubor et al., 2000; Bhat et al., 2008).

Least gelation capacity (LGC) The concentration required for developing of a 'self-supporting' gel is known as LGC. According to Boye et al. (2010), LGC is considered as a significant index of gelling capacity. Overall, a better gelling capacity is indicated by a lower LGC. Results of LGC are presented in Table 1. In the present study, Bario rice was able to form a better gel at lower concentration (8\%), followed by white and basmati rice (at $10 \%$ ), black and brown rice (at 12\%) and glutinous (at 14\%). According to Ikpeme et al. (2010), compared to other cereal flour such as wheat flour, rice has similar least gelation capacity. The observed differences in LGC can be related to the presence of varied levels of proteins, carbohydrates and lipid in the various rice samples (Sathe et al., 1982; Kaur et al., 2007; Yeom et al., 2009).

Emulsifying activity and Emulsion stability (EA and ES) Results on the EA and ES of different rice varieties investigated in the present study are shown in Figure 1 (C, D). Results indicated that glutinous rice to have considerably high EA when compared to white rice, which can be attributed to the presence of high protein content. However, there was not much difference in the ES among all the rice samples investigated. It has been reported that cell wall (endosperm) of milled rice to encompass large amounts of pectin substances, which are good emulsifying and stabilizing agents (FAO, 1992). Additionally, Panyam and Kilara (1996) have reported macro peptides to provide higher ES, while micro peptides can reduce the ES.

Results on emulsion properties are important, as they are closely associated with protein solubility and protein surface hydrophobicity, which can prevent and eliminate any bonding between lipid and protein components found in rice grain (Damodaran, 1996; Travis et al., 2000). The results of this study clearly indicates the possible usage of rice in various food industries as binders due to its excellent emulsion stability, thus capable of holding all the ingredients together (Toriyama et al., 2005).

Total starch content and pasting properties In this study, among the different rice varieties, black rice had the lowest total starch content followed by glutinous rice. Whereas, white rice had highest total starch content, which can be attributed to the retrogradation of amylose molecules (Adu-Kwarteng et al., 2003). On heating starch in presence of water, physico-chemical changes occur in the molecule that include breaking of hydrogen bonds. This allows water to enter the granule leading the granule to swell and rupture. After this, crystallinity is disoriented and amylose leaching occurs from the grain. It is reported that certain distinct features can affect granule swelling integrity with relation to rigidity of gelatinized starch granules (Sandhya and Bhattacharya, 1989; Suh et al., 2004). The swollen granules as well as leached amylose are reported to contribute to their pasting properties (Morris, 1990).

Results on pasting properties of different rice starches evaluated in the present study are summarized in Table 2. The pasting temperature (onset of the rise in viscosity) for rice samples ranged from 62.1 to $78.3^{\circ} \mathrm{C}$ with the lowest being recorded for black rice and the highest for white rice. The peak time ranged from 5.3 to $9.2 \mathrm{~min}$. Earlier, Sompong et al. (2011) have reported that rice with high amylose content to have a peak time above $8 \mathrm{~min}$. In addition, starch with a short peak time has been reported to swell up and disintegrate more (Tsakama et al., 2010).

The maximum viscosity obtained by gelatinized starch during heating in water is known as peak viscosity (PV). PV signifies the water binding capacity of a starch granule (Shimelis et al., 2006).

Table 1. Foaming capacity and least gelation Capacity of rice varieties investigated in the present study

\begin{tabular}{lllllll}
\hline \multicolumn{7}{c}{ Rice varieties } \\
\hline Parameter & White & Brown & Bario & Black & Glutinous & Basmati \\
\hline Foaming Capacity & 0.97 & 2.97 & 1.98 & 1.98 & 3.96 & 0.97 \\
LGC (\%) & 10 & 12 & 8 & 12 & 14 & 10 \\
\hline
\end{tabular}

LGC, Least Gelation Capacity. Values are mean of three independent replicates $(n=3)$. (The statistical differences were not shown, hence not highlighted). 


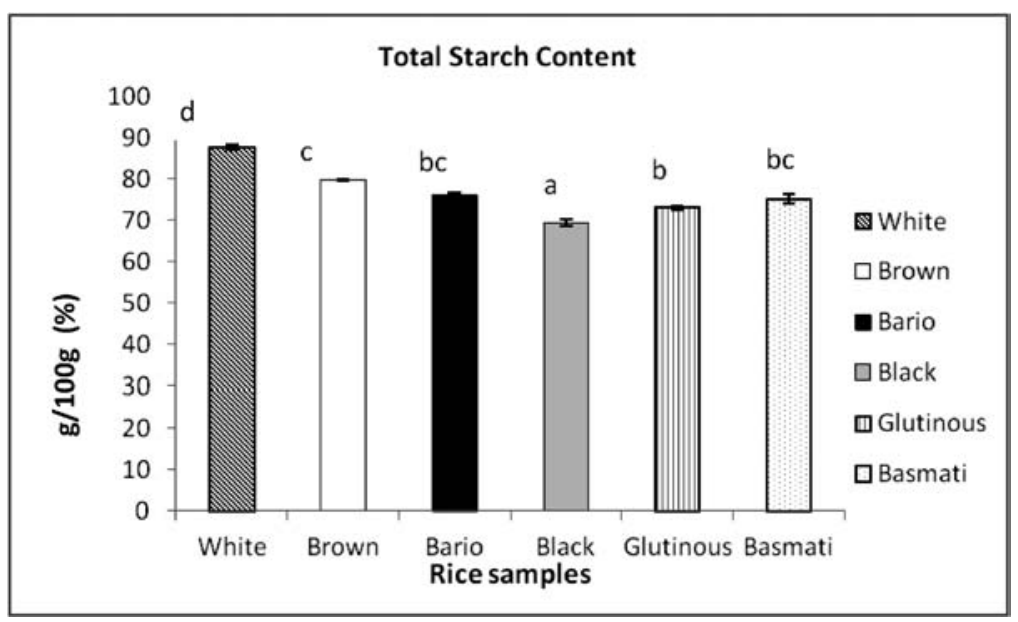

Fig. 2. Total starch content of rice varieties evaluated in the present study. Values are mean \pm standard deviation, same letter superscripted in the same column are not significantly different from each other at $p<0.05$.

Table 2. Pasting Properties of rice varieties investigated in the present study ( $n=3 \pm$ S.D.)

\begin{tabular}{lcccccc}
\hline Rice samples & $\begin{array}{c}\text { Pasting Temperature } \\
\left({ }^{\circ} \mathrm{C}\right)\end{array}$ & $\begin{array}{c}\text { Peak time } \\
(\mathrm{min})\end{array}$ & $\begin{array}{c}\text { Peak Viscosity } \\
(\mathrm{cP})\end{array}$ & $\begin{array}{c}\text { Breakdown } \\
(\mathrm{cP})\end{array}$ & $\begin{array}{c}\text { Final Viscosity } \\
(\mathrm{cP})\end{array}$ & $\begin{array}{c}\text { Setback } \\
(\mathrm{cP})\end{array}$ \\
\hline White & $73.5 \pm 0.23^{\mathrm{c}}$ & $9.2 \pm 0.14^{\mathrm{f}}$ & $729 \pm 0.32^{\mathrm{e}}$ & $345 \pm 0.11^{\mathrm{d}}$ & $1077 \pm 0.21^{\mathrm{e}}$ & $561 \pm 0.76^{\mathrm{e}}$ \\
Brown & $64.2 \pm 0.14^{\mathrm{b}}$ & $5.3 \pm 0.13^{\mathrm{a}}$ & $298 \pm 0.27^{\mathrm{a}}$ & $127 \pm 0.34^{\mathrm{a}}$ & $513 \pm 0.23^{\mathrm{a}}$ & $281 \pm 0.16^{\mathrm{c}}$ \\
Bario & $78.3 \pm 0.24^{\mathrm{d}}$ & $8.1 \pm 0.1^{\mathrm{e}}$ & $339 \pm 0.65^{\mathrm{b}}$ & $246 \pm 0.24^{\mathrm{b}}$ & $589 \pm 0.71^{\mathrm{b}}$ & $351 \pm 0.32^{\mathrm{d}}$ \\
Black & $62.1 \pm 0.32^{\mathrm{a}}$ & $6.2 \pm 0.2^{\mathrm{b}}$ & $435 \pm 0.89^{\mathrm{c}}$ & $215 \pm 0.43^{\mathrm{b}}$ & $618 \pm 0.13^{\mathrm{c}}$ & $212 \pm 0.14^{\mathrm{a}}$ \\
Glutinous & $63.8 \pm 0.1^{\mathrm{ab}}$ & $6.9 \pm 0.09^{\mathrm{c}}$ & $413 \pm 0.21^{\mathrm{c}}$ & $202 \pm 0.09^{\mathrm{c}}$ & $598 \pm 0.14^{\mathrm{b}}$ & $264 \pm 0.19^{\mathrm{b}}$ \\
Basmati & $72.5 \pm 0.12^{\mathrm{c}}$ & $7.2 \pm 0.09^{\mathrm{d}}$ & $662 \pm 0.34^{\mathrm{d}}$ & $354 \pm 0.43^{\mathrm{d}}$ & $813 \pm 0.32^{\mathrm{d}}$ & $296 \pm 0.31^{\mathrm{c}}$ \\
\hline
\end{tabular}

Values are mean \pm standard deviation, $p<0.05$ ). Same letter superscripted in the same column are not significantly different from each other at $p<0.05$.

In the present study, PV was recorded to be highest in white rice $729 \mathrm{cP}$ and lowest in brown rice $298 \mathrm{cP}$.

Breakdown viscosity, which is a measure of disintegrated cooked starch granules (Agu et al., 2006), ranged from 127 to 354 cP with the lowest being for brown rice and the highest being Basmati rice. BC occurs when swollen starch granules are disrupted leading to amylose leaching during the holding phase at $95^{\circ} \mathrm{C}$ under shear. High values of BV indicates lesser breakdown of starch and is rather more inferior in handling heating and sheer stress during cooking process (Adebowale et al., 2005).

Re-association of starch molecules occurs when the mixture is cooled, consequently forming a gel leading to enhanced viscosity known (as the final viscosity). Final viscosity (FV) is commonly used as a quality parameter to measure the strength of a gel formed on cooling (Cornejo-Villegas et al., 2010). The range obtained for FV from this study was 513 to 1077 cP. The rapid increase in FV could be attributed due to the amylose chains attaining an ordered arrangement (Flores-Farias et al., 2000).

Setback, which is associated with the retrogradation and consistency of a gel formed by starch molecules, can provide valuable informations especially when high amylose starches are retrograded (Karim et al., 2000). In other words, setback can be considered as the measure of recrystallization attained by gelatinized starch while cooling. Results of the present study showed that setback was highest in white rice, followed by Bario, Basmati, brown, glutinous and black rice. According to Mutters et al. (2009), rice with low amylose content can have a low setback.

With regard to the results obtained for pasting properties, except for the glutinous rice, all other rice varieties showed significantly higher pasting properties. The differences observed in pasting properties of starch can be attributed to variations in amylose and lipid contents as well as the differences in the amylopectin structure such as chain length, degree of polymerization, etc (Wang et al., 2001; Gupta et al., 2009). According to Simi and Abraham (2008), dissimilarity between the two factors in amylopectin structure can influence gel viscosity, consistency and gel strength. Additionally, the size of starch granules can influence pasting properties. It has been reported that gelatinization to be slower in smaller starch granules owing to the formation of extra molecular bonds (Chen et al., 2003). According to Zhou et al. (2002), higher temperature is required for gelatinization when internal molecular structures are stronger. 


\section{Conclusions}

Investigations conducted on six different rice varieties (local and imported in Malaysia) indicated differences in the functional and pasting properties. The functional properties of rice varieties showed significant differences in water and oil absorption capacity, with less significant difference in emulsion stability. The percentage of starch content varied significantly with the lowest starch yield obtained from black rice and the highest from white rice. The peak time, peak viscosity, final viscosity and setback were highest in black rice, which can be attributed to their high amylose content. Overall, from the results obtained, understanding the functional and pasting properties of local rice varieties is expected to aid in the development of new rice based food products.

Acknowledgements The first author would like to thank Universiti Sains Malaysia, for the funding provided (from graduate assistantship) throughout the study.

\section{References}

Adebowale, A.A., Sanmi, L.O., and Awonorin, S.O. (2005). Effect of texture modifiers on the physicochemical and sensory properties of dried fufu. Food Sci. Technol. Int., 5, 373-382.

Adu-Kwarteng, E., Ellis, W.O., Oduro, I., and Manful, J. T. (2003). Rice grain quality: A comparison of local varieties with new varieties under study in Ghana. Food Cont., 14, 507-514.

Agu, R., Bringhurst, T., and Brosnan, J. (2006). Production of grain whisky and ethanol from wheat, maize and other cereals. J. Inst. Brewing, 112, 314-323.

Akubor, P. I., Isolokwu, P.C., Ugbane, O., and Onimawo, I.A. (2000). Proximate composition and functional properties of African breadfruit kernel and wheat flour blends. Food Res. Int., 33, 707-712.

Arora, G., Sehgal, V.K., and Arora, M. (2007). Optimization of process parameters for milling of enzymatically pre-treated Basmati rice. J. Food Eng., 82, 153-159.

Barron, J. (2010). The Baseline of Health Foundation Black Rice Bran, the Next Superfood? Natural Health Blog. http://www.jonbarron.org/article/ black-rice-bran-next-superfood. (Accessed date: $20^{\text {th }}$ September 2012).

Beuchat, L.R. (1977). Functional and electrophoretic characteristics of succinylated peanut flour proteins. Agric. Food Chem. 25, 258-261.

Bhat, R., Sridhar, K.R., Young, C.C., Bhagwath, A.A., and Ganesh, S. (2008). Composition and functional properties of raw and electron beamirradiated Mucuna pruriens seeds. Int. J. Food Sci. Technol., 43, 13381351.

Bhattacharjee, P., Singhal, R.S., and Kulkarni, P.R. (2002). Basmati Rice: A review. Int. J. Food Sci. Technol., 37, 1-12.

Bligh, H.F.J. (2000). Detection of adulteration of Basmati rice with nonpremium long-grain rice. Int. J. Food Sci. Technol. 35, 257-265.

British Dietietic Association (BDA). (2011). Weblink: www.bda.uk.com/ foodfacts (Accessed date: $30^{\text {th }}$ September 2011).

Boye, J., Zare, F., and Pletch, A. (2010). Pulse proteins: Processing, characterization, functional properties and applications in food and feed. Food Res. Int., 43, 414-431.

Chen, Z., Schols, H., and Voragen, A. (2003). Starch granule size strongly determines starch noodle processing and noodle quality. J. Food Sci., 68, 1584-1589.

Coffman, C.W. and Garcia, V.V. (1977). Functional properties and amino acid content of protein isolate from mung bean flour. Food Technol., 12, 473-484.

Cornejo-Villegas, M. A., Acosta-Osorio, A. A., Rojas-Molina, I., GuriérrezCortéz, E., Quiroga, M. A., Gaytán, M., Herrera, G., and RodríguezGarcía, M. E. (2010). Study of the physicochemical and pasting properties of instant corn flour added with calcium and fibers from nopal powder. J. Food Eng., 66, 401-409.

Cuevas-Rodriguez, E.O., Verdugo-Montoya, N.M., Angulo-Bejarano, P.I., Milam-Carrillo, J., Mora-Escobedob, R., and Bello-Perez, L.A. (2006). Nutritional properties of reknown flour from quality protein maize (Zea Mays L). LWT, Food Sci. Technol., 39, 1072-1079.

Damodaran, S. (1996). Functional property, In S. Nakai and H.W. Modler (eds.). Food protein properties and characterization. VHC Publishers, New York pp. 167-234.

FAO Corporate Document Repository. (1992). Rice in human nutrition. Agriculture and Consumer Protection.

FAO Corpotate Document Repository. (1998). Fermented fruits and vegetables. A global perspective. Agriculture and Consumer Protection.

Fasoyiro, S. B., Akande, S. R., Arowora, K. A., Sodeko, O. O., Sulaiman, P. O., Olapade, C. O., and Odiri, C. E. (2010). Physico-chemical and sensory properties of pigeon pea (Cajanus cajan) flours. African J. Food Sci., 4, 120-126.

Flores-Farias, F., Martinez-Bustos, Y., Salinas-Moreno, Y.K., Chang, J.S., Hernandez, J.G., and Rios, E. (2000). Physicochemical and rheological characteristics of commercial nixtamalised Mexican corn flours for tortillas. J. Sci. Food Agric., 80, 657-664.

Goni, I., Gracia-Diz, L., Manas E., and Saura-Calixto F. (1996). Analysis of resistant starch: A method for foods and food products. Food Chem. 56, 333-337.

González, R.J., Livore, A., and Brigitte Pons, B. 2004. Physico-chemical and cooking characteristics of some rice varieties. Brazilian Arch. Biol. Technol., 47, 71-76.

Guan, X., Yao, H., Chen, Z., Shan, L., and Zhang, M. (2007). Some functional properties of oat bran protein concentrate modified by trypsin. Food Chem., 101, 163-170.

Gupta, M., Bawa, A., and Semwal, A. (2009). Morphological, thermal, pasting, and rheological properties of barley starch and their blends. Int. J. Food Prop., 12, 587-604.

Hasjima, J., Enpeng, L., and Sushil, D. (2013). Milling of rice grains: Effects of starch/flour structures on gelatinization and pasting properties. Carbohydr. Polym., 92, 682-690.

Houston, D. F., Hill, B. E., Garrett, V. H., and Kester, E. B. (1963). Rice quality measurement, organic acids of rice and some other cereal seeds. J. Agric. Food Chem., 11, 512-517.

Ihegwuagu, N.E., Omojola, M.O., Emeje, M.O., and Kunle, O.O. (2009). 
Isolation and evaluation of some physicochemical properties of Parkia biglobosa starch. J. Pure Appl. Chem. 81, 97-104.

Ikpeme, E. C. A., Osuchukwu N. C., and Oshiele, L. (2010). Functional and sensory properties of wheat (Aestium triticium) and taro flour (Colocasia esculenta) composite bread. African J. Food Sci., 4, 248-253.

Islam, M.Z., Taneya, M.L.J., Shams-Ud-Din, M., Syduzzaman, M., and Hoque, M.M. (2012). Physiochemical and functional properties of brown rice (Oryza Sativa) and Wheat (Triticum aestivum) flour and quality of composite biscuit made thereof. The Agriculturists, 10, 20-28.

Iturriagaa, L.B., Mishimaa, B.L., and Añonb, M.C. (2010). A study of the retrogradation process in five argentine rice starches. Food Sci. Technol. 43, 670-674.

Juliano, B.O. (1985). Criteria and test for rice grain qualities. Rice: Chemistry and Technology, $2^{\text {nd }}$ edition, B.O. Juliano, (Ed). American Association of Cereal Chemistry: St. Paul, MN, USA, pp. 443-524.

Juliano, B.O. and Hicks, P. A. (1996). Rice functional properties and rice food products. Food Review International, 12, 71-103.

Karim. A.A., Norziah M.H., and Seow C.C. (2000). Methods for the study of starch retrogradation. Food Chem., 71, 9-36.

Kaur, M., Singh, K., and Singh, S.N. (2007). Comparative study of the functional, thermal and pasting properties of flours from different field pea (Pisum sativum L.) and pigeon pea (Cajanus cajan L.) cultivars. Food Chem., 104, 259-267.

Khuwijitjaru, P., Nualchan, P., and Adachi, S. (2007). Foaming and emulsifying properties of rice bran extracts obtained by subcritical water treatment. Silpakorn Uni. Sci. Technol. J., 1, 7-12.

Lawal, O.S., Adebowale, K.O., and Oderinde, R.A. (2004). Functional properties of amylopectin and amylose fractions isolated from bambarra groundnut (Voandzeia subterranean) starch. African J. Biotech., 3, 399404.

Marerat, M., Powan, P., and Singthongym, J. (2011). Functional properties of rice bran and its application in bread. 12th ASEAN Food Conference pp. 289-295.

MoniQA (2012). A European commission funded initiative within the sixth framework programmeTopicT5A.5.1: Quality and safety control strategies for food (NCE). Validation ring trial: determination of freshness and ageing of brown rice. http://www.moniqa.eu/rice. (Accessed date: $1^{\text {st }}$ January 2013).

Morris, V. I. (1990). Starch gelation and retrogradation. Trends Food Sci. Technol. 7, 2-6.

Mutters, R.G. and Thompson, J.F. (2009). Rice quality handbook. University of California (USA), Agriculture and Natural Resources. pp. 12-13.

Narayana, K. and Narasinga Rao, M. S. (1982). Functional Properties of Raw and Heat Processed winged bean flour. J. Food Sci., 47, 1534-1538.

Noorlidah, A., Nawawia, A., and Othman, I. (2000). Fungal spoilage of starch-based foods in relation to its water activity (aw). J. Stored Prod. Res., 36, 47-54.

Oshodi, A.A. and Adeladun, M.O.A. (1993). Proximate composition, some nutritionally valuable minerals and functional properties of three varieties of Lima bean (Phaseolus lunatus Linn.) flour. Int. J. Food Sci.
Nutr., 43, 181-185.

Panyam, D. and Kilara, A. (1996). Enhancing the functionality of food proteins by enzymatic modification. Trends Food Sci. Technol., 7, 120125.

Perez, L.A.B., Marbel, C.R.S., Rhebeca, R.M., Javier, S.F., and Antonio, J.A. (2002). Functional and chemical properties of modified starch from banana (USA paradisciaca). Agrocieniacia, 36, 169-180.

Ramesh, M. Murugiah, V., and Gupta, A.K. (2009). Efficient (in vitro) plant regeneration via leaf base segments of (indica) rice (Oryza sativa L.). Indian J. Expt. Biol., 47, 68-74

Sage V Foods. (2000). From weblink: http://www.sagevfoods.com. (Accessed date: $20^{\text {th }}$ December 2012).

Sandhya, M.R. and Bhattacharya, K.R. (1989). Rheology of rice-flour pastes: effects of variety, concentration, temperature and time of cooking. J. Text. Stud., 20, 127-137.

Sathe, S. K. and Salunkhe, D. K. (1981). Functional properties of Great Northern bean (Phaseolus vulgaris). J. Food Sci. 46, 71-75.

Sathe, S.K., Desphande, S.S., and Salunkhe, D.K. (1982). Functional properties of lupin seed (Lupinus mutabilis) protein and protein concentrates. J. Food Sci., 47, 491-497.

Sengupta, T. and Damodaran, S. (1998). Role of dispersion interactions in the adsorption of proteins at oil-water and air-water interfaces. Langmuir, 14, 6457-69.

Shimelis, E., Meaza, M., and Rakishit, S. (2006). Physicochemical properties, pasting behaviour and functional characteristics of flours and starches from improved bean (Phaseolus vulgaris L.) varieties grown in East African. CIGR E- Journals 8, 1-18.

Simi, C. and Abraham, E. (2008). Physicochemical Rheological and Thermal Properties of Njavara Rice (Oryza sativa) Starch. J. Agric. Food Chem., 56, 12105-12111.

Sompong, R., Siebenhandl-Ehn, S., Linsberger-Martin, G., and Berghofer, E. (2011). Physicochemical and antioxidative properties of red and black rice varieties from Thailand, China and Sri Lanka. Food Chem., 124, 132-140.

Suh, D. S., Verhoeven, T., Denyer, K., and Jane, J. (2004). Characterization of nubet and franubet barley starches. Carbohydr. Polym., 56, 85-93.

Tang S., Hettiarachychy N.S., Horax R., and Eswaranandam S. (2002). Physicochemical properties and functionality of rice bran protein hydrolyzate prepared from heat-stabilized defatted rice bran with the aid of enzymes. J. Food Sci., 68, 152-157.

Theerakulkait, C., Chaiseri S., and Mongkolkanchanasiri, S. (2006). Extraction and some functional properties of protein extract. Kasetsart $J$. (Nat. Sci.), 40, 209-214.

Toriyama, K., Heong, K.L., and Hardy, B. (2005). Rice is life. Scientific Perspectives for the $21^{\text {st }}$ Century. Proceedings of the World Rice Research Conference, Tsubaka, Japan. In IRRI (eds). pp. 280-282.

Travis, A.F., Mills, E.N.C., and Wilde, P. (2000). Protein-lipid interactions at interfaces. Grasas y Aceites, 51, 50-55.

Tsakama, M., Mwangwela, A.M., Mananiand, T.A., and Mahungu, N.M. (2010). Physicochemical and pasting properties of starch extracted from eleven sweet potato varieties. African J. Food Sci. Technol., 1, 90-98. 
Wanchanaa, S., Toojindaa, T., Tragoonrungb, T., and Vanavichit A. 2003. Duplicated coding sequence in the waxy allele of tropical glutinous rice (Oryza sativa L.). Plant Sci., 165, 1193-1199.

Wang, L.F., Wang, Y.J., and Porter, R. (2001). Structures and physiochemical properties of six wild rice starches. J. Agric. Food Chem., 50, 2695-2699.

Wass, G. (2011). Corporate activity and human rights in India. Published by human rights law network. pp.114.

Williams P., Yu P., and Poulson V. (2002). New Applications for Rice
Flour. Rice CRC Final Research Report.

Yeom, H.J., Lee, E.H., Ha, M.S. Ha, S.D., and Bae D.H. (2010). Production and physicochemical properties of rice bran protein isolates prepared with autoclaving and enzymatic hydrolysis. J. Korean Soc. Appl. Biol. Chem., 53, 62-70.

Zhou, Z., Robards, K., Helliwell, S., and Blanchard, C. (2002). Review: Composition and functional properties of rice. Int. J. Food Sci. Technol., 37, 849-868. 